Artigos 



\section{Das letras às virtudes: os jesuítas e a conformação do bom governo no México (séculos XVI-XVII)*.}

Anderson Roberti dos Reis ${ }^{* *}$

Resumo: Duas características, entre outras, marcaram as missões jesuíticas na Nova Espanha e, sobretudo, no México, entre os séculos XVI e XVII. A primeira dizia respeito à dedicação dos inacianos às tarefas educativas na capital e, por conseguinte, à sua relação com os grupos letrados que se formaram durante o período colonial. A segunda referia-se à influência e participação dos padres na formação da sociedade nos assuntos ligados ao governo do vice-reino. Para além da interpretação segundo a qual os jesuítas teriam formado a elite política criolla, que ocuparia os principais cargos administrativos e eclesiásticos, este artigo pretende estabelecer uma relação entre o ensino ministrado pela Companhia de Jesus no México, e notadamente as matérias constantes das classes inferiores, e a conformação de uma noção de bom governo. Para tanto, perseguimos nos documentos institucionais da Ordem e no conjunto epistolar relativo à Província Mexicana os laços que interligavam a formação literária dispensada aos jovens mexicanos ao cultivo das virtudes - consideradas as peças centrais do bom governo.

Palavras-chave: Jesuítas. Educação. Bom governo. Retórica. Nova Espanha.

\footnotetext{
* Este artigo é uma versão modificada e ampliada de um trecho do quinto capítulo de minha tese de doutorado (A Companhia de Jesus no México: educação, bom governo e grupos letrados. Séculos XVI-XVII), defendida na Universidade de São Paulo em 2012, sob a orientação da Profa. Dra. Janice Theodoro. Esta pesquisa contou com financiamento parcial da FAPESP, a quem agradecemos. ** Professor Adjunto do Departamento e do Programa de Pós-Graduação em História da Universidade Federal de Mato Grosso. E-mail: dosreiss@gmail.com.
} 


\section{Introdução}

Um aspecto tornou singulares as missões jesuíticas no México, pelo menos durante as três décadas que se seguiram à sua chegada à capital do vice-reino, em 1572. Tratava-se, se assim podemos enunciá-lo, do público-alvo para o qual os padres voltaram suas atenções. Se as demais ordens religiosas, assentadas na cidade havia meio século, tinham zelado pela salvação das almas indígenas, quase sempre inconstantes (VIVEIROS DE CASTRO, 2002, p. 181 e ss.), os inacianos dedicaram seus esforços, dia e noite, aos adolescentes e jovens crioulos. Além da catequese propriamente dita, os jesuítas enfrentaram o desafio que até então não havia sido sobrepujado: educar os filhos dos espanhóis, que estavam no México para cumprir a missão maior da Coroa: colonizar o Novo Mundo e cristianizar os gentios daquelas paragens. Um cronista da Ordem escreveu no início do século XVII que, assim, seus irmãos preenchiam o vazio deixado pelas outras ordens religiosas (SÁNCHEZ BAQUERO, 1945, p. 42-43), franciscanos e dominicanos principalmente, resgatando da vida ociosa e repleta de vícios aquela juventude que haveria de se integrar e conduzir a sociedade que então se organizava.

Eis uma imagem feita cuja circulação teve grande fortuna entre os historiadores (profissionais, ou não) que examinaram o período colonial da América ibérica: os jesuítas, a exemplo de sua trajetória na Europa, tomaram para si a educação dos crioulos (no caso europeu: dos filhos das elites políticas e econômicas), aproximando-se, portanto, dos grupos abastados e letrados da sociedade que seriam responsáveis por exercer as principais funções administrativas do vice-reino. Nas palavras do ensaísta Ángel Rama (1985, p. 41), para tomar um exemplo, os jesuítas teriam educado os segmentos que deveriam dar continuidade ao "sistema ordenado" da Monarquia no Novo Mundo. E esse seria o aspecto que explicaria primordialmente a influência, sobretudo política, da Companhia de Jesus no México por quase duzentos anos - elemento que, quando analisado isoladamente à luz das críticas “esclarecidas” à Ordem e da expulsão dos padres no século XVIII, parece se revestir de verdade absoluta suficiente para cobrir todo o período colonial. 
Afinal de contas, expulsar da América os jesuítas e negociar com o papa a extinção de sua Ordem significava, para a Coroa espanhola governada pela dinastia dos Bourbon, golpear duramente uma das instituições mais poderosas, que mais ameaçavam o enquadramento dos grupos crioulos às novas políticas da Monarquia.

Tal avaliação, se correta, pode muito bem ser aplicada às tensões que atravessaram os longos governos de Felipe $\mathrm{V}$ e de Carlos III, em meados do século XVIII. Porém, e este é o exercício que gostaríamos de fazer aqui, para os dois séculos anteriores, queremos pensar a influência dos jesuítas sob outros critérios. Em vez de nos basearmos na imagem feita, de uma Ordem religiosa que educou os crioulos para que ocupassem os postos administrativos no vice-reino a fim de consolidar uma ordem política estabelecida por Castela, desejamos recuar um passo e compreender os fundamentos do ensino jesuítico e suas próprias finalidades, para então pensar, valendo-nos dessas percepções, quais poderiam ter sido as influências daqueles padres para além das imagens feitas. Isto é: a proposta é entender o que significava ensinar aquilo que era previsto no curriculum, e com métodos específicos, no universo hispano-americano da segunda metade do século XVI e início do XVII.

A hipótese que orienta esse exercício se apoia nas percepções acerca da dimensão política e, mais especificamente, dos aspectos constitutivos de certa ideia de governo. O caminho parece ser este: se queremos avaliar as influências dos jesuítas na administração política do vice-reino, devemos pensar sua atuação conforme a cultura política de seu tempo. Assim, nossa hipótese é que o cerne da influência jesuítica - da educação jesuítica, sejamos claros - no âmbito político novo-hispânico decorre da contribuição daqueles padres para a conformação do bom governo por meio do ensino das letras. Ou seja, em vez de pensar a educação como meio para alcançar um fim específico - a manutenção da ordem imposta pela Monarquia -, queremos inscrevê-la na lógica do bom governo: a educação (literária) entendida como a forja encarregada de moldar homens virtuosos, que, em conjunto, seriam responsáveis pelo governo do reino - ou melhor, acompanhando o vocabulário dos próprios jesuítas, pelo governo das repúblicas de índios e de espanhóis. Nesse caso, tanto o ensino 
ministrado pela Companhia de Jesus como a ideia de governo não seriam meios para se chegar a um estágio tautológico do poder por ele mesmo.

Essa proposição não se sustenta numa utopia a respeito da ação missionária ou numa espécie de fantasia aristocrática. Ela se fundamenta na reflexão sobre as tensões entre as ideias de governo (regimen) e estado, ou razão de estado, durante os séculos XVI e XVII. Foi Michel Senellart quem, mais recentemente, levantou essa questão de modo enfático em seu livro As artes de governar (2006), cuja primeira edição em francês é de 1995. Tomando como ponto de partida as análises elaboradas por Michel Foucault em seus cursos no Collège de France durante a segunda metade dos anos 1970 - a saber: Em defesa da sociedade. Cursos de 1975-1976 (2010), Segurança, Território, População. Cursos de 1977-1978 (2008b) e Nascimento da Biopolitica. Cursos de 1978-1979 (2008a) -, Senellart põe à prova as hipóteses foucaultianas sobre a concorrência entre razão governamental e governamentalidade para afirmar que no século XVI as artes de governar, a despeito do Príncipe maquiaveliano, não haviam sucumbido por completo. Três anos antes de Michel Senellart recuperar o fôlego dos cursos de Foucault, alguns dos quais ele mesmo se encarregaria de publicar na década seguinte, o historiador italiano Maurizio Viroli, trilhando as sendas metodológicas e teóricas formuladas por Quentin Skinner, publicava seu From politics to reason of state (2009), no qual argumentava que, do século XIII ao século XVII, ocorrera uma mudança na linguagem política que assinalava a passagem (e a concorrência) de uma ideia (e de suas práticas correlatas) de política associada ao bom governo ("a" Política) à outra, ligada à razão de estado.

Longe de querer examinar detidamente esses e outros autores ${ }^{1}$, é nosso intuito apenas apontar para o espectro mais amplo do qual se origina nossa hipótese. De modo mais claro: se o princípio da razão de estado, e portanto toda a lógica da manutenção do poder, não prevalece sobre as "artes de governar" no século XVI, no caso de darmos crédito a nossos autores, por que deveríamos partir de uma premissa diferente da que sugere que a educação jesuítica, tributária da tradição escolástica e humanista predominante na península itálica entre os séculos XIII e XVI, inscrever-se-ia nos quadros do bom governo? Se quisermos alterar a pergunta, e torná-la mais 
próxima do contexto que nos interessa, podemos enunciá-la assim: por que partir da proposição que o ensino ofertado pelos padres no México servia mais para a manutenção do "sistema ordenado" da Monarquia castelhana do que para a formação de homens virtuosos responsáveis pelo governo das repúblicas?

As perguntas e as hipóteses estão lançadas. Para responder aquelas com base nos caminhos sugeridos por estas, organizamos o presente texto em três partes. Na primeira, investigamos as relações gerais entre letras e virtudes na tradição partilhada pelos jesuítas no século XVI. Em seguida, estendemos tal análise para o par "educação literária-bom governo", percorrendo os documentos produzidos pelos inacianos em busca dos elos que podem unir esses dois termos. Na terceira parte, à qual acompanha um encerramento, esmiuçamos os chamados "estudos inferiores" (ou classes inferiores), compostos por gramática, humanidades e retórica, a fim de explicitar a relação entre o ensino dessas matérias e conformação do bom governo no México.

\section{Letras e virtudes}

A tradição humanista consagrou a ideia de que as letras são as artes que corrigem e aperfeiçoam a natureza. Nesse argumento, apropriado pelo programa educativo da Companhia de Jesus, estava implícito o pressuposto aristotélico expresso no segundo livro da Etica a Nicômaco de que as virtudes intelectuais e morais não surgem em nós por natureza. Aquelas nascem por meio do ensino, por isso necessitam de tempo e experiência; e estas brotam pelos hábitos. Assim, os homens adquirem as virtudes:

[...] pelo exercício, como também sucede com as artes. Com efeito, as coisas que temos de aprender antes de poder fazê-las, aprendemo-las fazendo; por exemplo, os homens tornam-se arquitetos construindo e tocadores de lira tangendo esse instrumento. Da mesma forma, tornamo-nos justos praticando atos justos, e assim com a temperança, a bravura, etc. (ARISTÓTELES, 1987, p. 27) 
Como se sabe, essa concepção geral da virtude fundamentou o "projeto" de educação humanista - e notadamente o dos "humanistas do norte", como foram denominados pelo historiador Quentin Skinner (2006) os que não tinham origem na península Itálica -, assentado nos studia bumanitatis, o programa que abrangia o ensino de gramática, retórica, história, poesia e filosofia moral baseado na tradição clássica grega e romana.

De maneira geral, acreditava-se que havia uma estreita relação entre litterae et virtus, e entre as palavras e aquilo que elas expressavam e representavam. Valendo-se dessa perspectiva, por exemplo, enfatizava-se a capacidade singular dos homens de falar e, pois, de organizar-se em comunidade, conforme lia-se na Política (1999), de Aristóteles, e depois no primeiro capítulo do livro I do De regno (2004), de Tomás de Aquino: está na capacidade de falar a razão do poder político, já que os homens são os únicos que podem expor, por meio das palavras, o que é conveniente e inconveniente, o que é justo e injusto e, assim, expressar sua percepção do bem, do mal, da justiça e da injustiça, a fim de buscar as melhores condições para a vida em comum. No livro I da Política (1999, p. 146), lemos o seguinte:

Por conseguinte, é evidente que o Estado é uma criação da natureza e que o homem é, por natureza, um animal político. [...] A natureza, como se afirma frequentemente, não faz nada em vão, e o homem é o único animal que tem o dom da palavra. E mesmo que a mera voz sirva para nada mais do que uma indicação de prazer ou de dor, e seja encontrada em outros animas (uma vez que a natureza deles inclui apenas a percepção de prazer e de dor, a relação entre elas e não mais do que isso), o poder de palavra tende a expor o conveniente e o inconveniente, assim como o justo e o injusto. Essa é uma característica do ser humano, o único a ter noção do bem e do mal, da justiça e da injustiça. E é a associação de seres que têm uma opinião comum acerca desses assuntos que faz uma família ou uma cidade. 
Essa mesma percepção, de matriz grega, perpassou o contexto romano - sobretudo nos textos de Cícero e Quintiliano ${ }^{2}$, que foram amplamente lidos, relidos e estudados entre os séculos XIV e XVI por humanistas, filósofos, teólogos, moralistas e padres - e chegou até o ambiente hispano-americano do século XVI. Exemplo de apropriação da premissa greco-latina encontra-se na obra do jesuíta José de Acosta, que esteve no Peru e no México no final dos Quinhentos. Esse religioso reafirma o postulado da palavra como expressão da racionalidade interna na conhecida classificação dos bárbaros em sua obra De Procuranda Indorum Salute, de 1576, e no quarto capítulo do sexto livro de sua Historia Natural y Moral de las Indias, de 1590, em que o padre faz ilações sobre a organização dos indígenas com base no domínio que os nativos tinham das letras e da escrita.

Essas observações servem menos para esboçar uma história da epistemologia ou das relações entre linguagem e pensamento, e mais para fixar um ponto que nos parece importante: as letras, bem como seus correlatos - as linguagens escrita e falada, os impressos, a educação de maneira geral etc. -, não se dissociavam de uma dimensão política e ética. Pelo contrário, o domínio das letras, em sentido lato, permitiria ao indivíduo organizar e expressar corretamente seu pensamento e, ao mesmo tempo, corrigir seus vícios e defeitos. Desse modo, tal indivíduo poderia tanto participar da vida em comunidade ("ensinando, aprendendo, comunicando, discutindo e julgando...”) como aprimorar-se internamente a fim de se tornar mais virtuoso. Como bem lembrou João A. Hansen (2006, p. 148-149), a palavra constituía uma espécie de "foro externo" que deveria refletir o "foro interno", representado pela consciência, e simultaneamente contribuir para a boa formação deste. Havia, portanto, uma relação de complementaridade entre o binômio "letras y virtudes" crucial à compreensão da perspectiva educacional dos jesuítas.

Essa relação entre ambos os termos tomou corpo de diversos modos nas penas de humanistas e tratadistas dos séculos XV e XVI. Os "espelhos de príncipe" - e especialmente aqueles produzidos por autores cristãos para enfrentar o mais famoso speculum da história, O Príncipe, de Maquiavel $^{3}$ - desse período são exemplares 
nesse sentido, pois fundamentavam-se na ideia de que a boa educação e o correto aconselhamento dados aos governantes eram o melhor caminho para conduzi-los à virtude e, consequentemente, ao bom governo de seus Estados. O próprio princípio do espelho, na esteira da parenética à maneira de Sêneca, consiste em permitir ao observador saber o que ele é, mostrando-lhe, em seguida, o que ele deveria ser (SENELLART, 2006, p. 52). Assim, esse gênero literário articulava alguns elementos centrais da tradição humanista: a educação instilava, por meio das letras, virtudes que seriam o cimento do bom governo, cujo fim era o bem público (SKINNER, 2006, p. 247 e ss.).

Além dos aconselhamentos aos príncipes, a educação destinada à nobreza, aos magistrados e às demais camadas da sociedade era considerada essencial à boa governança de uma república. Tratadistas como Juan Luis de Vives e Erasmo insistiram nos benefícios da educação das crianças e dos jovens, partilhando da mesma lógica dos "espelhos" quanto à relação entre educação, letras e virtudes (traduzidas, muitas vezes, nos "bons modos"). No universo católico e reformado do final do século XVI, o jesuíta espanhol Juan de Mariana, em seu tratado Del Rey y de la Institución Real, de 1599, repercutia essas ideias e se perguntava acerca da formação infantil:

\footnotetext{
¿No hemos de poder esperar que con una educación rígida han de corregirse [las malas inclinaciones] y hasta cambiarse en virtudes? El hierro con el frecuente roce se desgasta y muda el orín en esplendor y en brillo; los cayados de los pastores, rectos por su naturaleza, toman una forma curva merced á los esfuerzos del arte; ¿qué importa que no podamos reformar por completo un carácter, con tal que podamos con la educación atenuar y corregir sus vicios? (MARIANA, 1854, Livro II, 1, p. 497)
} 


\section{Educação literária e bom governo}

A noção de bom governo partilhada no universo hispano-americano do século XVI pressupunha, de modo geral, a existência de ações e medidas justas (e, pois, virtuosas) por parte dos monarcas e dos demais "corpos" que integravam o Estado em busca do bem comum (LEMPÉRIÈRE, 2004). Nesse sentido, governar bem deveria necessariamente ser o resultado de uma prática moral - a condução adequada dos homens para um fim conforme sua natureza - orientada para o bem público. Se considerarmos, então, à medida que observamos os traços que delineavam a tradição humanista acima mencionada, que a educação literária era uma das formas de atenuar e corrigir os vícios, e de estimular as virtudes, devemos supor que as letras, o cultivo das virtudes e a ideia da boa governança vinculavam-se de algum modo. A hipótese que perseguimos neste artigo sustenta que a educação oferecida pelos jesuítas constituía o elo entre tais dimensões. Porém, devemos perguntar, de que modo se dava tal amálgama? Como as classes inferiores - às quais se limitou a maioria dos adolescentes e jovens que tomou assento nas instituições educativas da Companhia - poderiam forjar uma ideia de bom governo por meio da educação literária, disseminando valores, normas e práticas capazes de ordenar a sociedade civil que se formava na capital do vice-reino?

Para buscar uma resposta a essa questão, voltemos nossa atenção, ainda que brevemente, à organização geral dos estudos nos colégios jesuítas - e, notadamente, às chamadas classes inferiores. As matérias que integravam o currículo jesuíta nesse nível eram um desdobramento dos studia humanitatis, com alguns ajustes. Enquanto estes contemplavam a gramática, a retórica, a história, a poesia e a filosofia moral, o plano da Companhia deixava a filosofia moral para o âmbito das classes superiores - assim como a lógica, a parte do trivium medieval não contemplada naquela etapa -, reunindo as demais matérias em três núcleos: gramática, humanidades (poética e história) e retórica. Não se tratava de desvalorizar a lógica ou a filosofia moral, mas apenas de postergar seu ensino (agrupado nos cursos de artes) para a ocasião em que os jovens dominassem as litterae. Antes mesmo da sistematização da Ratio 
Studiorum, as Constituições da Ordem enfatizavam que eram "de muito proveito os estudos humanísticos de várias línguas, a lógica, a filosofia natural e moral, a metafísica, a teologia escolástica e positiva, e a Sagrada Escritura" (COMPANHIA DE JESUS, 2004, $\mathrm{IV}, 5,1$, p. 125). Mais adiante, aquele texto remarcava:

\begin{abstract}
Tendo em vista que os nossos colégios não devem ajudar a instruir-se nas letras e nos bons costumes só os próprios escolásticos, mas também os de fora, onde convenientemente se puder fazer instituam-se aulas públicas ao menos de estudos humanísticos, e mesmo de estudos superiores, conforme as possibilidades que houver nas regiões onde se encontram tais colégios [...]. (COMPANHIA DE JESUS, 2004, IV, 7, 1, p. 131)
\end{abstract}

Três aspectos são importantes nesse trecho, porque influenciam significativamente as práticas da Ordem no México. Em primeiro lugar, a aproximação das letras com os bons costumes, o que se tornou praticamente uma tópica na correspondência entre Roma e a América; em seguida, a ênfase na formação dos "de fora", os alunos externos, como foram chamados na documentação jesuítica da Província Mexicana; por fim, a orientação para que se instituíssem ao menos as aulas públicas de estudos humanísticos, a pedra angular de todo o edifício. Essas normas gerais, que poderiam e deveriam ser adaptadas às diferentes regiões em que os padres atuassem, regulamentaram a fundação e a organização dos estudos inferiores no México. O primeiro responsável pela composição do curso de latinidades foi o padre italiano Vicente Lanuchi, que chegara àquela província em setembro de 1574. As aulas de gramática ficaram a cargo do Pe. Francisco Sánchez e de outros quatro irmãos, enquanto o próprio Lanuchi encarregou-se das leituras de retórica até 1579 (OSORIO ROMERO, 1979, p. 20).

O trabalho de organização iniciado pelo padre Lanuchi e pelos primeiros leitores de latinidades continuou nos anos 1580, sob a coordenação do padre Bernardino de Llanos, um dos mais eminentes compositores desse período (KARNAL, 1998, p. 119 e ss.). Até a sistematização dos estudos nos anos 1590, com a edição 
da Ratio Studiorum, o método de ensino na Província Mexicana respondia, pelo menos parcialmente, às instruções gerais das Constituições e às orientações expedidas em Roma: cuidar das letras e virtudes, bem como atender aos de fora ${ }^{4}$ ao menos com as classes de humanidades. Parcialmente, porque houve dificuldades relativas à uniformização das práticas de ensino, à saúde dos professores e à escassez de livros, gerando muitas vezes críticas entre os próprios padres acerca da qualidade das aulas (OSORIO ROMERO, 1979, p. 45-46). Contudo, um aspecto parecia certo: a necessidade de se vincular as letras às virtudes.

Durante a Primeira Congregação Provincial da Ordem no México, em 1577, o tema veio à tona algumas vezes e, em especial, nos debates sobre a fundação de um colégio em Michoacán. Primeiramente, o provincial Pedro Sánchez questionou se tal medida "convernía a el servicio de N. Señor y bien común desta república" - pergunta para a qual já se sabia a resposta - e depois propôs que a Companhia de Jesus tomasse como modelo o Colégio Romano no que se referia à administração e ao regime. A solução encontrada foi a seguinte:

[...] pero porque [os escolares] no se sujetan tan bien como desea, ni tienen tanta industria, paresció a la congregación que, si en cada collegio biviese algún Padre con algunos Hermanos, sería el fructo sin comparación maior, así spiritual, letras y moral, como en policía y buen govierno. (MM, I, 112, p. 307) ${ }^{5}$

Esse trecho é representativo do modo como se concebia a atuação da Ordem nos colégios estabelecidos nas cidades. $\mathrm{Na}$ mesma formulação, o redator da ata, o Pe. Pedro Morales, dispôs os termos "bem comum", "república", "letras", "moral", "polícia" e "bom governo" - e tudo isso associado aos frutos sin comparación do ensino de letras e da presença de alguns padres ao lado dos estudantes. Na sequência, Morales arrematou o argumento: 
[...] que tener los Nuestros a estos estudiantes en custodia y regimiento y ocuparlos en letras y virtudes [...] se evitarían infinitos peccados que en tierra tan aparejada como esta se suele hazer desde la niñez, desde la qual les enseñaría a bivir christianamente y en mucha virtud (MM, I, 112, p. 308).

Nas Constituciones del Colegio de S. Pedro y S. Pablo, de 1582, encontramos disposições semelhantes. Naquele documento, escrito provavelmente pelo reitor Pedro Díaz, enfatizava-se que muitos proveitos eram esperados do Colégio do México, como a formação de ministros para os serviços da Igreja e para os ofícios espirituais e temporais. Além disso,

[...] la república [era] mucho honrrada y servida con la tal obra, pues le crían hijos doctos y virtuosos, y es cosa cierta que no ay mayor riqueza en una república, que aver muchas y doctas y buenas personas, aunque todo lo demás faltase; y por el contrario, no ay mayor pobreza en una república que aver falta de tales personas, aunque tenga gran riqueza y prosperidad. (MM, II, 45, p. 112)

Esse fragmento é lapidar porque evidencia a percepção que se tinha das razões que justificavam a criação dos colégios e das escolas. A ordem era a seguinte: educar os hijos significava torná-los doctos y virtuosos e, pois, personas doctas y buenas, fundamento de uma boa república, que seria rica - não em termos econômicos, resta claro, mas moral e politicamente. A ordem invertida também era verdadeira, segundo as Constituciones: a maior "pobreza" de uma república era não dispor de pessoas doctas (do latim doctus, particípio passado do verbo docere) e virtuosas, ainda que houvesse riqueza e prosperidade. Indivíduos virtuosos, bons e justos constituíam a base de uma república, de uma sociedade civil. Por si só, nem mesmo a educação seria suficiente se seu fim não fosse promover virtudes.

Em 8 de abril de 1596, o Pe. Geral Claudio Aquaviva escreveu ao reitor do Colégio do México, Diego García, para orientá-lo quanto ao que se esperava do cultivo das virtudes entre os 
jovens. Segundo o remetente, "Mucho encargo a V. R. el exacto cuydado de esa juventud y que, en primer lugar, cuyde de sacarlos muy virtuosos y sólidos; poque éstos, con pocas letras, harán mucha hacienda; y muchas letras sin santidad, harán nada o poco" (MM, VI, 5, p. 92). Novamente estabelecem-se os devidos pesos: as letras eram importantes à medida que conduzissem à virtude; sem esta, aquelas não teriam efeito, ao passo que uma pessoa virtuosa, com poucas letras, hará mucha hacienda. Não se tratava de desprezo pela educação literária em si, mas de uma exortação para que seus irmãos não negligenciassem a finalidade dos colégios e da missão jesuítica como um todo.

O texto definitivo da Ratio Studiorum de 1599 consolidou a relação entre letras e virtudes na esfera das classes inferiores, fazendo coro às vozes acima enunciadas. No primeiro item das "Regras do prefeito de estudos inferiores", dedicado à finalidade, há a seguinte orientação:

Entienda el Prefecto que ha sido elegido para ayudar al Rector con todo empeño en el gobierno y dirección de nuestras escuelas, de modo que los que las frecuentan aprovechen no menos en la rectitud de vida que en las bellas artes (COMPANHIA DE JESUS, 1992, p. 49, grifo nosso).

Mais adiante, nas Regras comuns para os professores das classes inferiores, lemos que:

A los adolescentes que han sido confiados a la educación de la Compañía, fórmelos el profesor de modo que, juntamente con las letras, vayan aprendiendo también las costumbres dignas de un cristiano. Dirija, pues, su especial intención, tanto en las clases cuando se ofreciere ocasión como fuera de ellas, a preparar las tiernas mentes de los adolescentes para el servicio y amor de Dios y de las virtudes, con que se le debe agradar. Observe empero principalmente lo que sigue. (COMPANHIA DE JESUS, 1992, p. 63) 
O cuidado com a "formação cristã", conclui-se, não era exclusividade dos prefeitos e professores dos estudos inferiores ${ }^{6}$. Todavia, a estrutura do plano de ensino jesuítico relegava-lhes o princípio dessa missão, pois tratava-se do início daquela formação, ou, em muitos casos, da única formação (em letras e virtudes) que aqueles jovens receberiam, considerando que vários deles não seguiam para o curso de filosofia e teologia. Nesse sentido, junto com as preleções, leituras, repetições e exercícios de memória, o professor deveria estar atento aos momentos de missas, orações, catequeses, devoções, exortações públicas e privadas, confissões e intercessões (COMPANHIA DE JESUS, 1992, p. 63-64). Essa observação atenta, somada ao ensino de gramática, humanidades e retórica, contribuiria para a gênese do bom cristão, fundamento de uma república "rica".

\section{A centralidade dos estudos inferiores}

Como temos sugerido, o influxo da educação jesuítica na conformação do bom governo pode ser buscado na concepção que se tinha do plano de estudos - herdeira das tradições escolásticas e humanistas - implementado pelos padres nos colégios mexicanos. Isto é, ao almejar a formação de "bons cristãos", os jesuítas contribuíam para a criação de certo ordenamento da sociedade civil pautado na disseminação, entre os alunos, de normas morais, valores e práticas - todos associados ao universo cristãocatólico do final do século XVI. Assim, antes mesmo de o jovem estudante concluir seus estudos e, letrado, buscar as possibilidades de ascensão social por meio de carreiras na burocracia ou na esfera eclesiástica, ocupando postos destinados à "elite", ele se submetia à formação em "letras e virtudes". Nessa formação, argumentamos, residem alguns dos elementos cruciais à compreensão da influência jesuítica nas cidades americanas, de modo geral, e no México, em particular.

Sabemos que o público dos colégios da Companhia na capital do vice-reino durante o período colonial foi formado majoritariamente por jovens crioulos provenientes de famílias ricas e influentes 
do México e de cidades vizinhas (GONZALBO AIZPURU, 1990, p. 143). Embora não houvesse nenhuma orientação na Ratio especificando o alvo dos jesuítas, as condições que envolveram a instalação da Ordem na Nova Espanha favoreceram tal público - na medida em que franciscanos e dominicanos ocupavam as regiões centrais da capital havia meio século e mantinham trabalhos missionários junto a boa parte das populações indígenas. Além disso, as próprias regras que presidiam a fundação de colégios sugeriam a aproximação entre a educação oferecida pelos padres e os setores mais abastados da sociedade, já que, para fundar um colégio, era necessário haver patrono e vecinos dispostos a colaborar com becas, para as quais eles indicavam candidatos. Os jovens indígenas, escravos ou dos setores pobres da população branca estiveram quase sempre impossibilitados de ingressar no Colégio Máximo. Do mesmo modo, sabemos que, do "currículo" previsto pela Ratio, dividido em dois "níveis" (inferior e superior), predominou o ensino das classes inferiores no colégio mexicano da Companhia de Jesus. Conforme lembrou Ignacio Osorio Romero (1979, p. 124), mais de oitocentos jovens seculares frequentaram as aulas no México, dos quais a maioria vestia becas aqules, destinadas aos estudantes de latim e retórica. De modo semelhante, Pilar Gonzalbo Aizpuru (1990, p. 202-203) enfatizou que, ao longo do século XVII, o "[...] colegio máximo de San Pedro y San Pablo, exponente de la alta intelectualidad de toda la provincia, se dedicó, como venía haciendo desde su fundación, a las humanidades; sus alumnos dominaron las técnicas de la retórica y de la poética".

É importante notarmos, portanto, a centralidade adquirida pelo ensino de latim e humanidades no colégio mexicano, fosse porque, invariavelmente, a maioria dos jovens crioulos limitava-se a essa etapa, fosse porque, sem aqueles conhecimentos, os estudantes não poderiam avançar para os cursos de artes e teologia. A relevância dessa observação está na compreensão que se tinha - de modo geral nas Constituições da Companhia e, depois, de maneira sistematizada. na Ratio Studiorum - dos significados do ensino de gramática, retórica e humanidades entre os séculos XVI e XVII. Com efeito, as classes de latinidades abriam pelo menos dois caminhos aos jovens: um, ligado à vida eclesiástica, à pregação 
e à oratória sacra; o outro, relativo à vida pública e à participação na administração civil. Ambos, contudo, fundamentavam-se na expressão ratio et oratio: era necessário pensar e falar bem, condição a que se poderia chegar por meio dos estudos inferiores. Para corroborar nossa hipótese - que sugere los estudios inferiores como o cerne da relação entre a educação jesuítica e o bom governo no México -, interessa-nos examinar, sobretudo, o segundo caminho franqueado pelo ensino de latinidade: o acesso à vida pública. Que laços uniam as lições de gramática, poesia e retórica (as letras) à participação na vida civil e, por conseguinte, à conformação do bom governo (resultado do cultivo das virtudes)?

Da herança humanista apropriada pelos jesuítas na organização de seus métodos de ensino, alguns aspectos nos ajudam a responder àquela questão. Inicialmente, cabe sublinhar a relevância atribuída ao ensino de gramática, considerada o meio para a imersão e o domínio do latim (e, em alguns casos, do grego), cujos propósitos eram os estudos bíblicos e o conhecimento dos autores clássicos da tradição greco-latina. Não custa lembrar, a título de exemplo, a concepção expressa pelo sevilhano Antonio de Nebrija, cuja obra foi utilizada nos colégios jesuítas do México, para quem “[...] a gramática é a arte ou ciência responsável pelo estudo da palavra enquanto signo que estabelece congruências, analogias, entre a racionalidade humana e o mundo real" (CORDEIRO, 2008, p. 120). E, à medida que permitia esmiuçar os signos e os elementos da fala que poderiam representar a racionalidade no mundo exterior, a ars grammatica possibilitava a congruência adequada entre pensar e falar bem.

A despeito das dificuldades enfrentadas pelos colégios mexicanos, principalmente com a escassez de livros nas bibliotecas durante as primeiras décadas, os jovens crioulos tiveram acesso a várias gramáticas e obras de referência. Segundo Ignacio Osorio Romero (1997, p. 24-25), saltavam à vista a ausência de textos medievais e a presença de gramáticas clássicas anotadas por autores como Erasmo ou Luis de Vives. Os humanistas europeus, cujo aprendizado ocorrera com as gramáticas medievais, optaram por escrever novos textos que superassem o material utilizado em suas formações, considerado "formal e abstrato" (BIGNOTTO, 2001, 
p. 153). Ainda de acordo com Osorio Romero, quatro gramáticas "formaram escola" entre os séculos XV e XVI: a de Lorenzo de Valla, a de Antonio de Nebrija, a de Juan van Spauteren, conhecido como o "Despauterio", e a do jesuíta português Manuel Álvarez. Destas, as gramáticas de Nebrija e Álvarez ${ }^{8}$ (cuja primeira impressão "mexicana" resultara dos esforços do Pe. Lanuchi, nos anos 1570) tiveram grande circulação entre os alunos dos colégios novo -hispânicos. O texto Elegantia latinae linguae, escrito por Valla entre 1435 e 1444, e as obras "pedagógicas" de Erasmo e Vives também chegaram ao México (OSORIO ROMERO, 1997, p. 25 e ss.).

Os métodos de ensino de gramática no Colégio Máximo quase sempre seguiram à risca as orientações organizadas na Ratio Studiorum, mantendo a divisão básica do curso em três graus: as classes ínfimas, médias e supremas ${ }^{9}$. Nesses níveis, os adolescentes aprenderiam os fundamentos sintáticos, as oito partes da oração (substantivo, pronome, verbo, particípio, advérbio, preposição, conjunção e interjeição), as construções figuradas e a métrica. Entre as lições, e muitas vezes durante as refeições, os "gramáticos" repetiam "de memória" os conteúdos aprendidos e compunham diálogos em prosa e éclogas em verso latino para serem lidos em público e corrigidos (OSORIO ROMERO, 1979, p. 26). Esses exercícios evidenciavam a importância atribuída à imitação, "método humanista por excelência” (GÓMEZ ROBLEDO, 1954, p. 17), já que o parâmetro de correção das lições era dado pelas obras utilizadas ao longo dos cinco anos dos estudos inferiores. Para os estudos de gramática e de seu complemento, as humanidades, os autores latinos mais lidos no México foram Cícero, Virgílio, Ovídio, Caio César, Terêncio e Salústio (OSORIO ROMERO, 1997, p. 63). Entre os gregos, destacaram-se os textos de Homero, Platão e Tucídides (GOMEZ ROBLEDO, 1954, p. 103-104), embora essas obras tenham circulado com menor vigor.

Independentemente do tema abordado por cada autor utilizado no Colégio Máximo, o objetivo de fundo dos cursos de gramática e humanidades era fornecer modelos clássicos que pudessem ser "imitados" pelos estudantes ${ }^{10}$. O princípio da imitação, com esse sentido, mobilizava a ideia de que o aperfeiçoamento nas letras humanas - evidenciado pela capacidade de escrever e falar bem - 
expressava a correção do pensamento e contribuía para o aprimoramento dos hábitos e, consequentemente, para a formação moral dos jovens - fim último da educação jesuítica, segundo notamos anteriormente. É nessa perspectiva que devemos entender a classe de humanidades, cujos métodos se assemelhavam aos das aulas de gramática. Ela constituía uma espécie de transição entre o conhecimento teórico e gramatical e sua aplicação prática com a ars rhetorica. Nesse nível, conforme instruía a Ratio Studiorum, os estudantes iniciavam-se nos rudimentos da eloquência com base em três eixos: o conhecimento da língua (enriquecimento do vocabulário), a aquisição de "moderada" erudição e a introdução à retórica por meio das obras de historiadores, poetas e oradores.

É interessante notar como esse plano de imersão na língua durante os quatro primeiros anos era atravessado por elementos de filosofia moral - que, conforme observamos, seria estudada mais adiante no curso de artes, estruturado com base na filosofia aristotélica - e, especialmente, por aqueles apresentados em Dos deveres (1999), de Cícero, leitura constante no Colégio Máximo do México. Nas Regras do professor de humanidades, previa-se:

Para el conocimiento de la lengua, que se basa principalmente en la propiedad y riqueza de vocabulario, explíquese en las prelecciónes diarias Cicerón solo de los oradores, y por lo general los libros que tratan de filosofía moral (COMPANHIA DE JESUS, 1992, p. 77).

No México, onde se usava o Dos deveres ainda nas clases inferiores, os livreiros importaram 26 exemplares daquela obra em 1576 e, oito anos mais tarde, outros dezenove volumes (OSORIO ROMERO, 1997, p. 61). Considerando-se o apreço devotado pelos jesuítas à narrativa ciceroniana, é bem provável que esses exemplares tenham se multiplicado ao longo do século XVII.

A presença do tratado Dos deveres no México não se justificava apenas por seu estilo eloquente, característica acentuada em outras obras de Cícero mais voltadas à oratória, como o Sobre o orador (2002). A particularidade daquele texto, escrito em 44 a.C., residia especificamente na evocação da "vida ativa" e do "homem 
cívico", cumpridor de certos "deveres", entre os quais o de pôr suas virtudes (sabedoria, justiça, coragem e moderação ${ }^{11}$ ) a serviço da vida pública e da administração da cidade. No livro I daquela obra, Cícero advertia quanto à relação entre ócio e negócio desde a perspectiva política:

Muitos há e houve que, buscando a serenidade de que falo, retiraram-se dos negócios públicos e refugiaram-se no ócio. [...] Esses acalentaram o mesmo propósito que os reis: não carecer de nada, não obedecer a ninguém e gozar de completa liberdade, isto é, viver como se queira. Semelhante atitude é própria tanto dos que cobiçam o poder quanto dos que, como eu disse, se entregam ao ócio; uns se julgam capazes de alcançar essa tranqüilidade se possuírem riquezas, outros se se contentarem não só com o seu, mas com o seu pouco. Não desprezemos a decisão de nenhum deles, mas reconheçamos que a vida dos ociosos é mais fácil, mais segura e menos molesta aos outros. Quanto aos que se adaptaram ao serviço da comunidade política e à realização de grandes tarefas, sem dúvida sua existência é mais frutifera para o gênero humano, como também mais propicia à fama e à grandeza. (CÍCERO, 1999, I, XX-XXI, 69-70, p. 36-37, grifo nosso)

Como observa-se, tratava-se da construção de uma "imagem positiva da cidadania” (SKINNER, 1999, p. 104), alicerçada na correlação entre o domínio das letras - que permitiria a participação na res publica por meio da deliberação - e o cultivo das virtudes. A vita activa ciceroniana adequava-se tanto à abordagem dos humanistas, de modo geral, como à dos jesuítas, que haviam descartado o modelo da vita contemplativa adotado por outras ordens religiosas.

A discussão moral e política a respeito dos cidadãos romanos, empreendida no texto Dos deveres, ressoava duplamente nos estudos inferiores aplicados aos colegiais mexicanos. Estudava-se o estilo - acentuando a construção e a argumentação, em prosa, presentes na obra - e também se disseminavam os preceitos morais ciceronianos - pautados na noção da participação pública como "deverser" dos membros de uma comunidade política. Nesse sentido, o 
emprego daquele tratado durante as classes de gramática e humanidades servia como um tipo de preparação dos jovens para o último ano dos estudos inferiores dedicado à retórica, que, sob nosso ponto de vista, constituía o ponto culminante daquela etapa da educação dos adolescentes na medida em que os formava visando às atividades públicas ligadas ao governo da cidade.

Conforme previa a Ratio Studiorum, as lições de retórica dividiam-se em três grandes temas: preceitos de oratória, estilo e erudição. Na primeira etapa, a Retórica de Aristóteles (e, por vezes, a Poética) e os "livros retóricos"12 de Cícero eram os textos básicos. Quanto ao estilo, recomendava-se "casi exclusivamente" a leitura de Cícero, ao passo que a erudição se alcançaria com as obras de historiadores e poetas, responsáveis por comunicar costumes e testemunhos dos povos em qualquer ramo do saber (COMPANHIA DE JESUS, 1992, p. 71). No Colégio Máximo, outros dois autores foram lidos: Quintiliano, e sua Institutio oratoria, e o jesuíta espanhol Cipriano Suárez, com a Arte rhetorica, de 1562, na qual passava em revista os fundamentos dos textos de Aristóteles, Cícero e Quintiliano, transformando-se num importante manual (OSORIO ROMERO, 1997, p. 61).

Os métodos que constituíam as aulas de retórica seguiam basicamente os mesmos critérios daqueles das classes de gramática e humanidades. Alternavam-se as preleções (sobre os preceitos e o estilo), as composições dos alunos (traduções do grego para o latim, "imitações" de grandes oradores e poetas, descrições) e as correções, intercaladas por exercícios de memória e por análises, comparações e decomposições de discursos, argumentos e preceitos. Aos sábados, a cada quinze dias, havia declamações privadas e, mensalmente, apresentações públicas: ações dramáticas, diálogos, éclogas (COMPANHIA DE JESUS, 1992, p. 71 e ss.).

Ao passo que as classes de gramática privilegiavam a imersão e o domínio da língua latina, permeada por preceitos morais extraídos de textos clássicos da antiguidade, o ensino de retórica sugeria uma "prática da língua". Com efeito, os sentidos atribuídos àquela matéria, desde a tradição aristotélica, inseriam-na no domínio da praxis, da ação, conectada, portanto, aos campos da ética e da política. Cabe lembrar, aqui, da distinção proposta por Aristóteles a 
respeito da praxis e da poiêsis, no livro VI de sua Ética a Nicômaco (1987, p. 103-105), a fim de esclarecer o significado daquele termo. Segundo o Estagirita, a sabedoria prática (o outro tipo de conhecimento, ao lado do científico) dividia-se em duas formas de conhecer: a tekné, que pode ser traduzida como técnica, arte ou ofício; e a phrônesis, cujo sentido se aproxima da ideia de discernimento e julgamento. Cada forma de conhecimento teria, pois, um modo de agir correspondente. À tekné equivalia a poiêsis, isto é, a fabricação, a produção, o ato de fazer uma obra, “[...] um objeto que não tem seu princípio, sua origem em si mesmo, mas em um agente que o produz" (BERTEN, 2004, p. 72), à maneira do artesão, por exemplo. E à phrônesis ligava-se a praxis, entendida como a ação cuja finalidade não era outra senão ela mesma: "[...] ao passo que o produzir tem uma finalidade diferente de si mesmo, isso não acontece com o agir, pois que a boa ação é o seu próprio fim" (ARISTÓTELES, 1987, p. 104), à maneira dos homens sábios, por exemplo. Nesse sentido, a praxis supõe um "agir ético", que só tem sentido na medida em que se relaciona com uma ação comum (BERTEN, 2004, p. 73). Nas palavras de Aristóteles (1987, p. 104):

[...] julga-se que é cunho característico de um homem dotado de sabedoria prática o poder deliberar bem sobre o que é bom e conveniente para ele, não sob um aspecto particular, como por exemplo sobre as espécies de coisas que contribuem para a saúde e o vigor, mas sobre aquelas que contribuem para a vida boa em geral.

Logo, se pensarmos a retórica no domínio da sabedoria prática e, pois, da praxis, teremos de admitir que ela, ao contrário do que o senso comum pode sustentar, não se restringia ou se identificava apenas com a "arte de persuadir sem finalidade". Mas, de outro modo, no domínio da ética, a retórica deveria impulsionar os homens a buscar o bem, o que se desdobrava, na esfera política, no convencimento dos concidadãos com a finalidade de chegar ao bem comum da cidade (um pacto, decisões sobre guerras, julgamentos etc.) (BEUCHOT, 1998, p. 12). Conquanto se possa argumentar que - desde Aristóteles ${ }^{13}$, passando pelos oradores romanos, 
padres da Igreja até chegar aos humanistas - houve diferentes interpretações sobre os usos da retórica, esta foi, invariavelmente, associada a uma prática que extrapolava o exercício tautológico de persuasão.

Essa inserção da retórica no horizonte da praxis explica por que os humanistas relacionaram, em geral, o domínio daquela arte ao bom governo das cidades e à busca pelo bem comum. Dialogando com Quentin Skinner, João Adolfo Hansen sublinhou o lugar da retórica entre os humanistas e, pensando nas elaborações de Brunetto Latini, realçou os vínculos da retórica com o governo da cidade:

A substituição do ensino de retórica baseado em regras epistolares pelo ensino das letras latinas propostas como modelos a serem imitados atingiu o auge no século XIV. Skinner propõe que é da fusão do modelo francês das auctoritates com o dos livros de aconselhamento escritos à maneira das regras da ars dictaminis que surgem textos em que a mistura dos registros produz uma sofisticação teórica caracterizada pelo maior cuidado com as próprias letras. Citações de Platão, Sêneca, Juvenal, Salústio e, principalmente, Cícero, juntam-se então a regras de conselho e comportamento. Por exemplo, a contínua citação de Cícero e a incorporação da ética aristotélica fazem Brunetto Latini afirmar que a principal ciência que tem relação com o governo da cidade é a retórica, como técnica da fala persuasiva (2006, p. 156).

Os principais autores "redescobertos" entre os séculos XIII e XVI enfatizavam tal ponto, como o próprio Aristóteles, em sua Retórica (2009, I, 4, p. 67-68), ao examinar as características do discurso deliberativo:

[...] las cuestiones sobre las que todos tratan y sobre las que hablan en público los que deliberan resultan ser principalmente cinco en número, y son las siguientes: las referidas a los recursos, a la guerra y la paz, a la salvaguardia del país, a las importaciones y exportaciones y a la legislación. 
Newton Bignotto (2001, p. 91) lembrou como Cícero, em Dos deveres, "[...] observa que não podemos deixar de lado o poder de um grande orador e a importância de se persuadir os membros de uma assembléia sobre o melhor caminho a ser seguido numa disputa envolvendo o bem público". Do mesmo modo, para ficarmos nos três autores estudados no Colégio Máximo, Quintiliano advertia na Institutio oratoria (1954, v. 4, XII, 7, p. 293, grifo nosso): "Or moi, l'orateur que je forme, je voudrais qu'il soit philosophe, mais un philosophe romain, se montrant un homme dévoué à ses concitoyens, non par des discussions entre quatre murs, mais par son expérience des affaires et dans pratique".

Mesmo fora dos círculos humanistas italianos, as "belas letras" e a retórica tornaram-se elementos centrais à concepção de educação. Entre a "nobreza cortesã ", a "educação completa em letras" constituiu uma tópica nos séculos XVI e XVII, conforme notou João Adolfo Hansen (2006, nota 21, p. 150-151):

O latim e o grego, as belas letras - a poesia e a história gregas e latinas -; a filosofia aristotélica, estóica, neoplatônica e escolástica; a retórica aristotélica e ciceroniana foram os principais instrumentos adotados para constituir um estilo de vida em que a inculcação de hábitos nobres (entendendo-se "nobreza" com o duplo sentido de "estamento" e "virtude") foram a meta principal. Mais que um fim em si, formando sábios e pedantes, lembrou Dominique Julia, as letras e a retórica foram utilizadas como meios para formar o futuro governante, propondo-lhe que era uma natureza superior e que sua educação esmerada o preparava para um tempo em que se tomaria a si mesmo como modelo das ações [...].

No México, por ocasião do initium do ano letivo de 1600-1601, Juan de Ledesma, à época leitor de gramática no Colégio Máximo e às vésperas de concluir o curso de teologia e de se consagrar sacerdote (MM, VII, 9, p. 21-57), discursou sobre "[...] como alcançar a verdadeira nobreza": por linhagem ou por estudos (OSORIO ROMERO, 1979, p. 113)? Nesse panorama, o ensino de retórica 
ganhava importância à medida que proporcionava a "inculcação" de bons hábitos, de virtudes, corrigindo eventuais vícios que poderiam incidir, inclusive, sobre os nobres "por linhagem"14.

Antes de voltarmos a examinar a retórica desde a perspectiva da praxis nos colégios mexicanos da Companhia, cabem algumas palavras sobre as características gerais da retórica fundamentadas na teoria aristotélica - e compartilhadas no meio hipano-americano. Em primeiro lugar, a retórica faz parte do campo da lógica, no qual a razão deve se sobrepor à vontade. Assim, ela se relaciona com a dialética, pois ambas pertencem ao domínio da argumentação, mas dela distancia-se na medida em que sua finalidade é descobrir o verossímil, ao passo que a dialética procura a verdade. Uma boa imagem para essa relação seria aquela esboçada por Mauricio Beuchot (1998, p. 14-19): o modo como a lógica argumenta em favor da verdade, por meio de silogismos, a retórica o faz em prol do verossímil, pelo recurso aos entimemas ${ }^{15}$.

Além de pertencer à esfera do provável, a retórica, em sua forma clássica, pressupõe a presença de um “juiz”, de uma terceira pessoa que observa certa "disputa" entre dois argumentadores e que deve ser convencida, ao passo que a dialética objetiva persuade apenas o oponente do "diálogo" (CHINCHILLA PAWLING; MENDIOLA MEJÍA, 2006, p. 35). Essa terceira pessoa pode ser um juiz (numa situação forense), uma assembleia (numa perspectiva republicana de deliberação), uma plateia (em caso de difamação) ou mesmo um leitor (por ocasião de disputas escritas) ${ }^{16}$. Por fim, ainda de acordo com os referidos historiadores (2006, p. 32), a retórica opera sempre com base na memória, comunicando conhecimentos armazenados por meio da exposição (dispositio e elocutio ${ }^{17}$ ) e da fabricação de um discurso. Nesse prisma, o horizonte retórico pouco abriria-se às novidades, abarcando, adaptando e fazendo circular elementos oriundos da tradição.

Isso posto, duas acepções de retórica eram compartilhadas pelos jesuítas, inclusive por aqueles que estavam no México. A primeira, em sentido estrito, era a retórica como a arte de falar bem, disseminada pelos manuais e presente nas aulas dos colégios. A segunda, em sentido mais amplo, era a retórica como prudência, que constituía o fundamento da educação e, sobretudo, do ensino de latinidade - também nos ambientes externos aos colégios e 
entre as elites cortesãs (CHINCHILLA PAWLING; MENDIOLA MEJÍA, 2006, p. 16). E aqui reencontramos a retórica no território da praxis, pois, para além do simples "falar correto e elegante", ela pressupunha um comportamento decoroso. No caso, decorum remete tanto à noção de "decência" como à de "conveniência" e configura aquilo que Ana Lúcia Oliveira (2003, p. 33-34) chamou de "imperativo de conveniência":

[...] que pertence simultaneamente ao campo retórico e ao campo moral, constitui a arte de julgar e de apreender a ocasião no momento certo, segundo as circunstâncias e os interlocutores; portanto, aparece naturalmente como uma arte de prudência e de adequação de discursos, que se tornará a bienséance do século XVII.

Vinculada à arte prudencial e, portanto, à capacidade de julgar segundo as circunstâncias e com discernimento, a retórica busca distinguir o verdadeiro do falso e definir o meio-termo justo $^{18}$. Essa ligação, herdada da tradição aristotélica, estava em perfeita sintonia com a teoria tomista, fundamental à concepção que tinham os jesuítas ${ }^{19}$, segundo a qual a retórica era uma das partes da prudência, tomada em sentido amplo ${ }^{20}$ :

Si tomamos la prudencia en un sentido amplio, implicando también la ciencia especulativa [...] podemos entonces asignarle como partes la dialéctica, la retórica y la física, conforme los tres modos del proceso científico: el primero, la demonstración, que da origen a la ciencia, y esto compete a la física, bajo cuyo nombre quedan comprendidas las ciencias especulativas; el segundo parte de lo probable y forma la opinión, que da origen a la dialéctica; el tercero, de ciertas conjeturas deduce una sospecha o una leve persuasión, lo cual incumbe a la retórica. Se puede, no obstante, decir que estos tres pasos pertenecen a la prudencia propiamente dicha, pues esta razona unas veces basándose en principios necesarios; otras, en cosas probables; a veces, también, incluso en conjeturas. (AQUINO, 2001, IIa. IIae., q. 48, p. 416-417) 
Conquanto Tomás de Aquino não aprofunde, nesse trecho, a análise sobre a retórica e sobre seu "caráter especulativo", essa arte passa a ser um dos modos pelos quais a prudência razona. Se a prudência, base para todas as virtudes morais, é a arte de decidir corretamente, a recta ratio agibilium (a reta razão aplicada à ação) - e não um tipo de cautela ou de precaução, segundo se pode pensar atualmente -, a retórica, parte integrante daquela virtude, contribui para tal deliberação e, desse modo, colabora para o estabelecimento das soluções justas. É precisamente nesse particular que se cruzam os campos retórico e moral, fazendo convergir o ensino de latinidade e a perspectiva do bom governo. Da mesma forma que os padres, à maneira de jurisconsultos, buscavam decidir justamente os conflitos que lhes eram apresentados, a formação em "letras" pretendia semear e cultivar virtudes entre os alunos, especialmente a prudentia, à qual os estudos de retórica se vinculavam, a fim de torná-los capazes de propor soluções adequadas conforme as circunstâncias. Eis uma grande influência do ensino jesuítico na formação sociedade novo-hispânica!

\section{Considerações finais}

Por fim, não podemos deixar de sublinhar que o ensino de retórica - bem como de todo o ciclo de latinidade e humanidades - entre quatro muros era complementado por exercícios literários públicos (previstos na quarta parte das Constituições da Companhia), cujo propósito era duplo: praticar os fundamentos teóricos estudados e inspirar sentimentos de piedade e devoção por meio dos assuntos abordados naquelas ocasiões. De acordo com Xavier Gómez Robledo (1954, p. 66-79), havia diversos tipos de exercícios, tais quais: o exame público ao final do ano letivo; a apresentação de discursos latinos, alegorias e tragicomédias; os colóquios e certames literários; os debates retóricos. Além desses, como lembra Ignacio Osorio Romero (1979, p. 25-26), também havia atos literários organizados para a recepção de autoridades - como o vice-rei ou o arcebispo - e festejos marianos, eventos nos quais "[...] se 
adornaban las paredes de la iglesia con colgaduras que ostentaban composiciones en verso latino y castellano y se pronunciaban una oración latina y un panegiris latino y español".

Pode-se imaginar o impacto que esses exercícios literários provocavam no México, principalmente pela presença constante de autoridades, que atraíam público e conferiam pompa àquelas ocasiões. Tais atividades eram responsáveis por disseminar temas, saberes e normas na medida em que a plateia não se limitava ao entretenimento passivo, mas era também convidada a julgar e discernir o que era bom ou ruim entre as teses defendidas, os colóquios apresentados, as peças encenadas etc. A prática retórica, como vimos, pressupunha sempre o juízo de terceiros diante de um impasse.

Em 1575, por exemplo, os jovens estudantes representaram uma tragicomédia sobre hereges que injuriavam a Igreja perante o vice-rei, Martín Enríquez, e os principales da cidade e das ordens religiosas (GÓMEZ ROBLEDO, 1954, p. 66-67). Vinte anos depois, em 1595, quando o vice-rei D. Gaspar de Zúñiga y Acevedo chegou ao México para substituir D. Luis de Velasco, os jesuítas expuseram um colóquio latino escrito por Bernardino de Llanos, por meio do qual apresentavam às autoridades sua perspectiva da educação na Nova Espanha.

Esse colóquio e os demais exercícios literários públicos não pretendiam apenas louvar a postura da Companhia na Nova Espanha, mas sugerir o que era bom para o governo da "república", nesse caso a educação da juventude. A depender da eficiência da argumentação desenvolvida em tal colóquio, o juízo do vice-rei e das demais autoridades poderia ser mais ou menos favorável à hipótese defendida. É nesse viés que vinculamos a educação jesuítica - e notadamente aquela oferecida nas clases inferiores de latinidade e humanidades - à conformação do bom governo. Assim, para encerrar este artigo, referendamos o ponto de vista de Ramón Kuri Camacho (2000, p. 50) em relação ao propósito do "discurso jesuíta" vinculado ao ensino (como docere, escrever e ensinar) no México: "[...] recordar los derechos y deberes del hombre, lo que está mal en el mundo. Discurso teológico, discurso político, el discurso jesuita invita a reformar las relaciones sociales. Es, con efecto, un proyecto de sociedad". 


\section{FROM THE LETTERS TO THE VIRTUES: THE JESUITS} AND THE CONFORMATION OF GOOD GOVERNMENT IN MEXICO (16 ${ }^{\mathrm{TH}}$ AND $17^{\mathrm{TH}}$ CENTURIES)

Abstract: During the 16th and 17th centuries, the Jesuit missions in New Spain, and especially in Mexico, were marked by two main characteristics among others. The first one concerned the Jesuit dedication to educational activities in the capital and, thereafter, its relationship with the literate groups formed during the colonial period. The second characteristic concerned the influence and participation of the priests in the formation of the society and governmental subjects in the Viceroyalty. Surpassing the interpretation that Jesuits would have educated the "criolla" political elite, which should take the main administrative and ecclesiastical positions, we propose to relate the educational system established by the Society of Jesus in Mexico, specially the subjects contained in the "clases inferiores", with the conformation of a notion about the "good government". For this purpose, we investigate the institutional documents of the Order and the epistolary from Mexican Province interrogating them about the ties that interconnected the literate education for young Mexican students with the promotion of the political virtues - considered the main feature of good government.

Keywords: Jesuits. Education. Good Government. Rhetoric. New Spain.

\section{Notas}

${ }^{1}$ Para outras entradas, introdutórias também, ao debate sobre a razão de estado no ambiente espanhol do século XVI, ver: Aznar (1990), Díaz (2002) e Fernández-Santamaría (1986).

${ }^{2}$ Em sua obra Sobre o orador (De oratore), da qual usamos uma edição española, Cícero (2002, I, 8, 32-33, p. 99-100) observou que "tan sólo en el hecho de hablar entre nosotros y ser capaces de expresar nuestras sensaciones mediante la palabra aventajamos particularmente a los animales. Por lo cual ¿quién no ha de admirar con razón esto y juzgar que en ello hay que esforzarse en particular y aventajar así a los hombres mismos en la única cosa en que los hombres aventajan a los animales? Mas para llegar a lo más importante ¿qué otra fuerza ha sido capaz, ya de congregar a los hombres en un solo lugar o hacerlos pasar de una vida salvaje y agreste a este tipo de vida propio de hombres en comunidad y, una vez establecidas las sociedades, diseñar las leyes, los tribunales y los procedimientos legales?". De modo semelhante, em Dos deveres (De officiis) (1999, v. I, XVI, 50, p. 28), Cícero reafirma aquele princípio: "Parece, contudo, que 


\section{Anderson Roberti dos Reis}

devemos antes investigar quais princípios da natureza são próprios da comunidade e da sociedade humana. E o primeiro é o que notamos no concerto universal do gênero humano. Seu vínculo é a razão e a palavra que, ensinando, aprendendo, comunicando, discutindo e julgando conciliam entre si os homens e agrupam-nos em uma comunidade natural".

${ }^{3}$ Podemos citar, nesse particular, o jesuíta Pedro de Ribadeneyra (1787), cujo Tratado de la Religión y Virtudes que debe tener el Principe Christiano para gobernar y conservar sus Estados, de 1595, talvez seja o exemplo mais bem acabado de resposta às proposições de Maquiavel.

${ }^{4}$ Segundo nos informa a historiadora Pilar Gonzalbo Aizpuru (1990, p. 164165), havia 300 alunos externos no Colégio de S. Pedro y S. Pablo frequentando as aulas de gramática no ano letivo de 1575-1576. No século XVII, conforme a mesma autora, esse número aproximou-se de 1000.

${ }^{5}$ Para facilitar a leitura, optamos por utilizar a abreviação "MM" para indicar a Monumenta Mexicana (editada por Félix Zubillaga), seguida sempre do número do volume em números romanos, do documento e da página, em números arábicos. ${ }^{6}$ Conforme notou João Adolfo Hansen (2010, p. 25), o lema da Ratio Studiorum de 1599, como um todo, era que a educação deveria "tornar mais homem". Isto é: "deve dar conta das três faculdades que, segundo a filosofia escolástica, definem a pessoal humana: a memória, a vontade e a inteligência. Ao fazê-lo, deve ensinar-lhes o autocontrole, visando a harmonia dos apetites individuais e a amizade do restante do corpo político do Estado".

${ }^{7}$ Em 1602, o rei Felipe III concedeu licença e privilégio para que o bisneto de Antonio de Nebrija, D. Agustín, imprimisse e vendesse aquela gramática por dez anos, evento saudado pelo provincial Francisco Váez, que recebera a Arte de Nebrija (MM, VII, 110, p. 597).

${ }^{8}$ A gramática do Pe. Manuel Álvarez era utilizada desde os primeiros anos após a fundação do Colégio de S. Pedro y S. Pablo e sua obrigatoriedade era realçada com frequência nas cartas e orientações expedidas em Roma, como se pode notar nas Ordenaciones de janeiro de 1592 (MM, IV, 72, p. 211). Na Ratio de 1599, definiu-se com clareza que o texto do Pe. Álvarez deveria ser usado sempre, a não ser nas situações em que ele parecesse ser exigente demais. Nesse caso, os provinciais poderiam adotar a Gramática romana ou compor uma obra específica para tal público.

${ }^{9} \mathrm{Na}$ Carta Ânua referente a 1604, o provincial mexicano, Pe. Ildefonso de Castro, refere-se a essa divisão e aos cuidados do maestro de retórica, Pe. Bernardino Llanos: "Los estudios menores se han adelantado, de nuevo, con tres libros de mucha variedad y erudición, que el padre maestro de rhetórica sacó a luz para provecho y commodidad de todos los estudios de latinidad y rhetórica, en que se recogieron diversos authores, en el primer cuerpo, preceptos curiosos y 
eruditos de que havía falta. En el segundo, authores de prosa, los, más clásicos y, en el tercero, authores assí mesmo de poesía que, fuera de ser accomodados para la letura de nuestros estudios, conforme al libro de Ratione Studiorum, han sido generalmente bien resevidos de la gente erudita y docta" (MM, VIII, 151, p. 513-514).

${ }^{10} \mathrm{O}$ princípio da imitação (imitatio), cuja gênese remetia ao universo humanista italiano dos séculos XIV e XV, não significava uma "cópia fiel", mas inspiração com base no conhecimento aprofundado dos métodos, dos recursos e das técnicas dos autores clássicos. É por isso que se afirmava, por exemplo, que a composição elaborada pelos estudantes era uma "versão" (DÍAZ; OVANDO, 1951, p. 16). Para uma reflexão sobre a imitatio, ver Cavalcante (2002, p. 12-14). 11 "Mas tudo o que é honesto nasce de uma de quatro partes. Com efeito, consiste ou no discernimento e na apreensão do verdadeiro, ou na manutenção da sociedade dos homens, e, atribuindo-se a cada um o que é seu, na fé dos contratos, ou na grandeza e resistência do ânimo elevado e invencível, ou na ordem e medida de todas as coisas feitas e ditas, nas quais se encontram a modéstia e a temperança" (CÍCERO, 1999, I, V, 15, p. 11).

12 Além dos clássicos De oratore, De inventione e dos discursos, a anônima Retorica ad Herennium (2005) - atribuída a Cícero até o século XV - também foi utilizada nos colégios jesuítas (CHICHILLA PAWLING; MENDIOLA MEJÍA, 2006, p. 41). A edição que usamos da Retorica ad Herennium adota Cícero como autor, motivo pelo qual nós a listamos na Bibliografia junto com as demais obras desse autor.

13 Iniciamos com Aristóteles, pois em sua obra há a "superação" das "desconfianças platônicas" a respeito da utilidade da retórica na vida política, evidenciadas, sobretudo, em diálogos como Górgias, no qual se atacam os pressupostos sofistas.

${ }^{14}$ No mesmo sentido, os historiadores Perla Chinchilla Pawling e Alfonso Mendiola Mejía (2006, p. 29) observaram que para "la elite de la vieja Europa, el aprender tiene como finalidad el hacerse. Educarse es cultivarse a uno mismo para adquirir la forma 'humana'. La retórica forma parte de esta concepción veteroeuropea del aprendizaje. Ella conforma la civilidad o educación moral del individuo socializado. Por eso, las universidades medievales, y aún hasta el siglo XVII, no enseñaban artes mecánicas, sino artes liberales”.

15 Pode-se definir o entimema, de modo simplificado e com base na teoria aristotélica apresentada na Retórica, como o correspondente retórico do silogismo - ou apenas como um silogismo inacabado. No lugar de apresentar claramente as duas premissas - de modo a produzir uma conclusão necessária -, a "estrutura entimemática" oculta uma das premissas, embora apresente a conclusão, forçando o ouvinte ou o leitor a, ele próprio, deduzir a premissa omitida. Desse 


\section{Anderson Roberti dos Reis}

modo, o entimema pressupõe que os envolvidos na discussão sobre determinada matéria partilhem a mesma "bagagem cultural", saberes equivalentes, para que se torne possível a "dedução" do elemento oculto.

${ }^{16}$ Esses exemplos referem-se à tipologia do discurso elaborada por Aristóteles (2009, I, 3, p. 63 e ss.) e repercutida quase sempre pelos demais teóricos. Quais sejam: o discurso judiciário, o deliberativo e o demonstrativo.

${ }^{17}$ Cinco qualidades ou habilidades, segundo a concepção clássica da retórica latina, eram exigidas do bom orador: a) inventio, descoberta das coisas verossímeis que tornam a causa possível; b) dispositio, organização e distribuição desses elementos; c) elocutio, acomodação das palavras e sentenças adequadas à "invenção"; d) memoria, firme apreensão das coisas, palavras e disposição; e) actio, moderação da voz, semblante e gestos durante a pronunciação.

18 'Etimologicamente, o substantivo discreto, como em 'o discreto', vem do particípio passado do verbo 'discernir'. O termo significa a qualidade intelectual do juízo capaz de penetrar no mais intrincado dos assuntos, como perspicuidade ou perspicácia, para distinguir o verdadeiro do falso e estabelecer o meio-termo justo que é próprio da prudência. A discrição relacionava-se intimamente ao talento intelectual da invenção, o engenho, definido nesse tempo como um talento natural em que convergem retórica e dialética, ou seja, a capacidade lógico-analítica da avaliação dos assuntos, como juízo dialético, que se acompanha de formas sintéticas ou agudas de expressão. Como uma categoria central dos Exercícios Espirituais, de Ignacio de Loyola, no mundo católico dos séculos XVI e XVII a discretio significava a capacidade lógica e ética do discernimento do juízo aconselhado pela luz natural da Graça inata" (HANSEN, 2006, nota 7, p. 135)

19 "Conquérir les âmes par la culture, avec toutes les ressources des arts libéraux, tel était pour Loyola le mot d'ordre de l'apostolat moderne. Mais les humanités ne doivent aucunement, dans son esprit, se substituer à la théologie: elles en assurent l'efficacité maximale. La présence des païens dans la culture chrétienne du prédicateur et de son public relève de la seule concession tactique. [...] Sans ambiguiité, des Constitutions de 1551 à la Ratio Studiorum de 1591, il s'agit de fonder la prédication sur la théologie scolastique de Thomas d'Aquin, rendue persuasive grâce à l'enseignement rhétorique d'Aristote, Quintilen et surtout Cicerón” (MOUCHEL, 1999, p. 449).

${ }^{20}$ Ressaltamos esse aspecto porque para são Tomás (2001, IIa. IIae., q. 47, a. 2, p. 401) a prudentia pertence exclusivamente ao "entendimento prático", ao passo que a retórica, a dialética e a física estariam no campo especulativo. Porém, no trecho citado, ele "amplia" o sentido da prudência de modo a acomodar os elementos relativos àqueles três modos do "processo científico". 


\section{Referências}

ACOSTA, Pe. José de. De Procuranda Indorum Salute. Madrid: Consejo Superior de Investigaciones Científicas, s.d.

. Historia Natural y Moral de las Indias. 3. ed. México DF: FCE, 2006.

AQUINO, São Tomás de. Suma de Teología. 4. ed. Madrid: Biblioteca de Autores Cristianos, 2001. 5 v.

- Tratado de la ley. Tratado de la justicia. Gobierno de los príncipes. México DF: Porrúa, 2004. (Edición de Carlos Ignacio González).

ARISTÓTELES. Ética a Nicômaco. São Paulo: Nova Cultural, 1987. (Coleção Os Pensadores).

. Política. São Paulo: Nova Cultural, 1999. (Coleção Os Pensadores).

. Retórica. Madrid: Alianza Editorial, 2009.

AZNAR, Fernando Navarro. El topos de la razón de estado en su desarollo ideológico. Anales de Derecho, Universidad de Murcia, n. 10, p. 103-128, p. 1987-1990. BERTEN, André. Filosofia politica. São Paulo: Paulus, 2004.

BEUCHOT, Mauricio. La retórica como pragmática y hermenéutica. Barcelona: Anthropos, 1998.

BIGNOTTO, Newton. Origens do republicanismo moderno. Belo Horizonte: UFMG, 2001.

CAVALCANTE, Berenice. Antigos e modernos: histórias de uma tradição. In: (Org.). Modernas tradições: percursos da cultura ocidental (séculos XV-XVII). Rio de Janeiro: Access, 2002. p. 1-84.

CHINCHILlA PAWLING, Perla de los Ángeles; MENDIOLA MEjÍA, Alfonso. La construcción retórica de la realidad como una "teoría de la modernidad”. La enseñanza de la retórica en los colegios de la Compañía de Jesús en la Nueva España. In: CORREA ETCHEGARAY, Leonor et al. La construcción retórica de la realidad: la Compañía de Jesús. México DF: Univ. Iberoamericana, 2006. p. 13-55.

CHOCANO MENA, Magdalena. La fortaleza docta. Elite letrada y dominación social en México colonial (siglos XVI-XVII). Barcelona: Bellaterra, 2000.

CÍCERO, Marco Tulio. Dos deveres. São Paulo: Martins Fontes, 1999.

. Sobre el orador. Madrid: Gredos, 2002.

- Retórica a Herênio. São Paulo: Hedra, 2005.

Anos 90, Porto Alegre, v. 21, n. 39, p. 201-235, jul. 2014 


\section{Anderson Roberti dos Reis}

- Tratado da república. São Paulo: Círculo de Leitores, 2008.

COMPANHIA DE JESUS. Constituições da Companbia de Jesus e normas complementares. São Paulo: Edições Loyola, 2004.

COMPAÑÍA DE JESÚS. Fórmula del Instituto de la Compañia de Jesús, aprobada y confirmada por los Sumos Pontifices Paulo III y Julio III. México DF: Provincia Mexicana de la Compañía de Jesús, s/d. Disponível em: <www.sjmex.org/DocumentosPDF/FormulaInstituto.pdf $>$. Acesso em: 7 maio 2010.

- Ratio atque institutio studiorum societatis Iesu. In: GIL, Eusebio. (Ed.). El sistema educativo de la Compañia de Jesús. Madrid: Universidad Pontificia de Comillas, 1992.

Ratio Studiorum. In: JULIA, Dominique (Ed.). Ratio Studiorum. Plan raisonné et institution des études dans la Compagnie de Jésus. Paris: Berlin, 1997.

CORDEIRO, Roberta Henriques R. Dominicanos e jesuítas na emergência da tradição gramatical quechua - Século XVI. 2008. Dissertação (Mestrado em Semiótica e Linguística Geral) - Faculdade de Filosofia, Letras e Ciências Humanas (USP), São Paulo, 2008.

DÍAZ, Elias. Razón de Estado y razones del Estado. Isegoría, n. 26, p. 131-179, 2002.

DÍAZ Y DE OVANDO, Clementina. El Colegio Máximo de San Pedro y San Pablo. México DF: Unam; IIE, 1951.

FERNÁNDEZ-SANTAMARÍA, Jose A. Razón de Estado y Política en el Pensamiento Español del Barroco (1595-1640). Madrid: Centro de Estudios Constitucionales, 1986.

FOUCAULT, Michel. Nascimento da Biopolítica. Curso dado no Collège de France (1978-1979). São Paulo: Martins Fontes, 2008a.

. Segurança, Território, População. Curso dado no Collège de France (19771978). São Paulo: Martins Fontes, 2008b.

. Em defesa da sociedade. Curso dado no Collège de France (1975-1976). São Paulo: Martins Fontes, 2010.

GÓMEZ ROBLEDO, Xavier. Humanismo en el siglo XVT: el sistema del Colegio de San Pedro y San Pablo. México DF: Jus, 1954.

GONZALBO AIZPURU, Pilar. Historia de la educación en la época colonial: la educación de los criollos y la vida urbana. México: Colmex, 1990.

HANSEN, João Adolfo. Educando príncipes no espelho. Floema, n. 2A, p. 133169, 2006. 
- A civilização pela palavra. In: LOPES, Eliane Marta T. et al. 500 anos de educação no Brasil. 4. ed. Belo Horizonte: Autêntica, 2010. p. 19-41.

KARNAL, Leandro. Teatro da fé: representação religiosa no Brasil e no México no século XVI. São Paulo: Hucitec, 1998.

KURI CAMACHO, Ramón. La Compañia de Jesús: imágenes e ideas. Scientia Conditionata, tradición barroca y modernidad en la Nueva España. México DF: Plaza y Valdés, 2000.

MARIANA, Juan de. Del rey y de la institución real. In: Obras del padre Juan de Mariana. Madrid: Rivadeneyra, 1854. t. II.

MOUCHEL, Christian. Les rhétoriques post-tridentines (1570-1600): la fabrique d'une société chrétienne. In: FUMAROLI, Marc. Histoire de la rhétorique dans l'Europe moderne (1450-1950). Paris: PUF, 1999. p. 431-497.

OLIVEIRA, Ana Lúcia. Por quem os signos dobram: uma abordagem das letras jesuíticas. Rio de Janeiro: EdUERJ, 2003.

OSORIO ROMERO, Ignacio. Colegios y profesores jesuitas que enseñaron latín en Nueva España (1572-1767). México: Unam, 1979.

. Floresta de gramática, poética y retórica en Nueva España (1521-1767). 1. reimp. México DF: Unam, 1997.

QUINTILIEN. Institution oratoire. Paris: Garnier Frères, 1954. 4 v.

RAMA, Ángel. Cidade das Letras. São Paulo: Brasiliense, 1985.

RIBADENEYRA, Pedro de. Tratado de la religión y virtudes que debe tener el principe christiano para gobernar y conservar sus estados contra lo que Machiavelo, y los políticos de este tiempo enseñan. Madrid: Oficina de Pantaleon Aznar, 1787.

SÁNCHEZ BAQUERO, P. Juan. Fundación de la Compañia de Jesús en Nueva España. México DF: Patria, 1954.

SENELLART, Michel. As artes de governar. Do regimen medieval ao conceito de governo. São Paulo: Editora 34, 2006.

SKINNER, Quentin. Razão e retórica na filosofia de Hobbes. São Paulo: Unesp, 1999. . As fundacõos do pensamento político moderno. 5. reimp. São Paulo: Companhia das Letras, 2006.

VIROLI, Maurizio. De la política a la razón de Estado. La adquisición y transformación del lenguaje político (1250-1600). Madrid: Akal, 2009.

VIVEIROS DE CASTRO, Eduardo. A inconstância da alma selvagem e outros ensaios de antropologia. São Paulo: Cosac \& Naify, 2002. 


\section{Anderson Roberti dos Reis}

ZUBILLAGA, Félix (Ed.). Monumenta Mexicana. Roma: Monumenta Historica Societatis Iesu, 8 v. v. I - 1956; v. II - 1959; v. III - 1968; v. IV - 1971; v. V - 1973; v. VI - 1976; v. VII - 1981; v. VIII - 1991 (Edición de Miguel Ángel Rodríguez).

Recebido em: 03/06/2013. Aprovado em: 03/09/2013. 
